Gut, 1988, 29, 963-968

\title{
Neurophysiological dysfunction in young women with intractable constipation
}

\author{
J S VARMA AND A N SMITH
}

From the University Department of Surgery/Urology and Wolfson Gastrointestinal Laboratories, Western General Hospital, Edinburgh

SUMMARY Fifteen women with intractable chronic idiopathic constipation dating from adolescence were investigated by anorectal manometry, neurophysiological evaluation of the conus medullaris and external anal sphincter. Comparison was made with $\mathbf{2 5}$ asymptomatic female control subjects. Urological disturbances were common amongst the constipated, in five of whom incidental lumbosacral spinal dysraphism was found. No differences in sphincter pressures or the rectosphincteric reflex were demonstrable between the two groups. Rectal defecatory sensation was blunted and the compliance was increased in the constipated group. The latency of the pudendo-anal reflex was significantly prolonged in idiopathic constipation, two women having an absent reflex $(>100 \mathrm{~ms})$. Mean motor unit potential duration of the external anal sphincter was not significantly prolonged in the eight constipated women tested. A central neurogenic deficit is postulated in some women with this disorder.

Constipation is a common complaint in gastroenterology clinics and meant by the patient to imply a variety of symptoms. ${ }^{1-3}$ Although some of these patients respond to a high fibre diet and judicious use of laxatives, a small proportion have constipation that is severe and persistent and remains unresponsive to all forms of treatment except enemas and large doses of cathartics. Severe constipation in young to middle aged adults, dating from adolescence, is almost entirely confined to women. ${ }^{-2 \times}$ A variety of physiological abnormalities have been postulated and described and attempts to correct them surgically have met with limited success. ${ }^{x \cdot 12}$

Many of these women have a failure of voluntary relaxation of the striated pelvic floor musculature during defecation resulting in an outlet obstruction. ${ }^{51113}$ The observation that they may also have functional urological abnormalities ${ }^{1+16}$ prompted this investigation of their anorectal and sacral spinal cord function.

Address for correspondence: Professor A N Smith. University Department of Surgery/Urology. Western General Hospital. Edinhurgh EH+2XU

Received for publication 12 February 1988
Methods

PATIENTS

Formal approval for the study was obtained from the Ethical Committee of the Lothian Health Board, Edinburgh, Scotland and informed consent was obtained from all the participants who comprised 15 women with intractable idiopathic constipation (age range $19-54$ years, mean 32 ). All gave a history of severe constipation starting in adolescence with a duration ranging from five to 45 years (mean 19.8). Almost all patients described difficult rectal evacuation. None had had previous abdominal or pelvic surgery. Full clinical investigation including biochemical and haematological screening, sigmoidoscopy, and barium enema had failed to define a cause for the constipation. Their symptoms were inconsistent with the irritable bowel syndrome. Hirschsprung's disease had been excluded by anorectal manometry in all the patients and by full thickness rectal biopsy in six. At the time of this study the frequency of the bowel movements of the constipated patients ranged from once per week to once every five weeks (mean, once every 19 days). Dietary and drug adjustments had been of little benefit. Three 
patients had to have regular enemas to encourage defecation. All the patients were on some form of laxative. Urological symptoms were elicited in 12 of the 15 patients. Frequency, urgency, urge, and stress incontinence were the commonest. Two patients had recurrent urinary tract infections and three nocturnal enuresis. The pattern of voiding was urgent but some had difficulty in voiding by volition. Twenty five female controls consented to manometric and electrophysiological investigations. Their ages ranged from $23-60$ years (mean 40 ). These patients had been admitted to hospital for investigations or surgery outwith the alimentary tract and had no bowel symptoms.

\section{RADIOLOGY}

All the patients had a standard double contrast barium enema performed to exclude an obvious organic cause for the constipation.

\section{MANOMETRY}

All the patients and subjects were requested to refrain from all but the most essential medication for 48 hours before the manometric and electrophysiological investigations.

Anal sphincter manometry was done using a conventional mircoballoon technique ${ }^{17}$ to measure physiological sphincter length, basal, and squeeze pressures. The presence of the rectosphincteric reflex (reflex relaxation of internal anal sphincter in response to rectal distension) was confirmed in all patients and controls. Proctometrograms ${ }^{1 \times}$ were done in 10 patients and a similar number of approximately age matched controls. Rectal volumes at sensation threshold, constant (defecatory) sensation and maximal tolerance were measured and rectal compliance calculated.

\section{ELECTROPHYSIOLOGY}

Measurement of the electrophysiological latency of the pudendo-anal reflex (PAR) was carried out by the averaging method described by Varma et al. ${ }^{19}$ It was elicited by electrical stimulation of the dorsogenital nerve with a felt bipolar surface electrode (type LBS 53051, Medelec, UK). The reflex contraction of the external anal sphincter was recorded with a bipolar surface stainless-steel anal plug electrode (type 13K78, DISA, Copenhagen) using the Medelec MS92a evoked-response unit. More than 100 square wave stimuli (duration $0 \cdot 1 \mathrm{~ms}$, frequency $2 \mathrm{~Hz}$ ) were applied and the digitally averaged response displayed on the oscilloscope at a sweep speed of $10 \mathrm{~ms} / \mathrm{cm}$ with the gain at 10 or $12 \mu \mathrm{V} / \mathrm{cm}$ and filter settings of $2 \mathrm{~Hz}-10 \mathrm{kHz}$. The stimulation voltage was approximately three times the voltage at sensation threshold. In no case was the stimulation reported to be painful.
The procedure was repeated in each subject to ensure reproducibility. The latency of the PAR was measured from the onset of the sweep (triggered by the stimulus) to the onset of the clearly defined reflex response at the external anal sphincter. ${ }^{19}$ The sensory threshold and stimulation voltages, amplitude, and duration of the reflex contraction of the external anal sphincter as determined by this method were also noted. Mean motor unit potential duration of the external anal sphincter was able to be carried out in eight patients and compared with data gathered from 15 control women. A modification of the method described by Bartolo et $a l^{211}$ was used. A standard concentric needle EMG electrode (surface area 0.07 $\mathrm{mm}^{2}$, type 13L49 DISA, Copenhagen) was inserted into the external anal sphincter without anaesthetic via a puncture site $1 \mathrm{~cm}$ lateral to the anal orifice to a depth of approximately $25 \mathrm{~mm}$. This was connected via preamplifiers to an oscilloscope (Medlec MS9a, Woking, Surrey, UK). The tonic electrical activity of the sphincter was monitored using a time base of 10 $\mathrm{ms} / \mathrm{cm}$ with the gain at $100 \mathrm{uV} / \mathrm{cm}$ and filter settings of $20 \mathrm{~Hz}-10 \mathrm{kHz}$ ). Single motor units firing at a steady rate were identified using the delay and trigger facilities incorporated in the apparatus. Approximately 100 consecutive action potentials of the same motor unit were digitally averaged on one channel of the oscilloscope and the process repeated on the second channel. When two identical traces were obtained on both channels, the action potential duration for that motor unit was measured from the first deflection from the baseline to the return of the action potential to the baseline. Stable late components were thus easily identified. Permanent recordings were obtained of at least 20 action potentials from the external anal sphincter representing approximately 10 recordings from each side of the sphincter. This was made possible by minor movements of the tip of the needle electrode in the sphincter. The arithmetic mean of the 20 recorded potential durations was calculated and represented the mean motor unit potential duration for that sphincter. This was used as an index of neuropathy. ${ }^{21}$

STATISTICAL ANALYSIS

Differences in the manometric and electrophysiological measurements between the groups were analysed by the Wilcoxon's rank-sum test.

\section{Results}

RADIOLOGY

In two patients barium enemas showed a redundancy of the sigmoid colon. No other colonic abnormality was detectable in any patient. In five of the 15 
Table 1 Manometric data in young women with intractable idiopathic constipation

\begin{tabular}{llll}
\hline Parameter & $\begin{array}{l}\text { Chronic } \\
\text { constipation }\end{array}$ & Control & $p$ \\
\hline & $(\mathrm{n}=15)$ & $(\mathrm{n}=25)$ & \\
$\mathrm{MRP}\left(\mathrm{cm} \mathrm{H} \mathrm{H}_{2} \mathrm{O}\right)$ & $101(4 \cdot 6)$ & $107(5 \cdot 6)$ & $>0 \cdot 1$ \\
$\mathrm{HPZ}(\mathrm{cm})$ & $3 \cdot 1(0 \cdot 1)$ & $3 \cdot 2(0 \cdot 1)$ & $>0 \cdot 1$ \\
$\mathrm{MVC}(\mathrm{cm})$ & $159(8)$ & $167(7)$ & $>0 \cdot 1$ \\
& $(\mathrm{n}=10)$ & $(\mathrm{n}=10)$ & \\
$\mathrm{STV}\left(\mathrm{ml} \mathrm{H}_{2} \mathrm{O}\right)$ & $348(56)$ & $230(35)$ & $>0 \cdot 1$ \\
$\mathrm{CSV}\left(\mathrm{ml} \mathrm{H}_{2} \mathrm{O}\right)$ & $444(40)$ & $300(28)$ & $<0 \cdot(12)$ \\
$\mathrm{MTV}\left(\mathrm{ml} \mathrm{H}_{2} \mathrm{O}\right)$ & $699(49)$ & $510(22)$ & $<0 \cdot 01$ \\
$\mathrm{RC}\left(\mathrm{ml} / \mathrm{cm} \mathrm{H}_{2} \mathrm{O}\right)$ & $14 \cdot 4(1)$ & $8 \cdot 5(0 \cdot 6)$ & $<0 \cdot 01$ \\
\end{tabular}

All measurements mean (SE); rectosphincteric reflex present in all patients and controls; $\mathrm{MRP}=$ maximum resting (basal) anal canal pressure; $\mathrm{HPZ}=$ length of sphincteric high-pressure zone;

$\mathrm{MVC}=$ maximum voluntary sphincter contraction pressure

$S T V=$ rectal volume at sensory threshold $; C S V=$ rectal volume at constant (defecatory) sensation; MTV = maximal tolerable rectal volume; $\mathrm{RC}=$ rectal compliance

patients, however, spinal dysraphism was noted incidentally; in several patients, satisfactory views of the lumbosacral spine were not available on the enema films for the exclusion of this disorder.

The spinal bony defects included defective closure of the dorsal neural arches of the first or second sacral vertebrae in three patients and of the fifth lumbar vertebra in two patients.

\section{MANOMETRY}

The manometric data are listed in Table 1. The rectosphincteric reflex was demonstrable in all the patients and controls with no significant differences in sphincter pressure or length.

Rectal compliance was increased in constipation. There appeared to be no deficit of rectal sensory threshold although the volume at which the desire to defecate (the constant sensation volume) was perceived was significantly increased in constipation, as was the maximal tolerable volume.

Table 2 Electrophysiological data in young women with intractable idiopathic constipation

\begin{tabular}{|c|c|c|c|}
\hline Parameter & $\begin{array}{l}\text { Chronic } \\
\text { constipation }\end{array}$ & Control & $p$ \\
\hline & $(n=15)$ & $(n=25)$ & \\
\hline Sensory threshold, PAR (volts) & $32 \cdot 7(1 \cdot 5)$ & $35 \cdot 2(2 \cdot 9)$ & $>() \cdot 1$ \\
\hline Stimulation strength, PAR (volts) & $103(5)$ & $112(6 \cdot 6)$ & $>() \cdot 1$ \\
\hline Latency PAR (ms) & $\begin{array}{l}50.7(1.9) \\
(2 \text { absent })\end{array}$ & $39(1 \cdot 2)$ & $<0 \cdot(01$ \\
\hline Amplitude PAR ( $\mu \mathrm{V})$ & $7 \cdot 1(1 \cdot 78)$ & $4 \cdot 5(0 \cdot 68)$ & $>0 \cdot 1$ \\
\hline External sphincter MUPD (ms) & $\begin{array}{l}(n=8) \\
10 \cdot 1(0 \cdot 7)\end{array}$ & $\begin{array}{l}(n=15) \\
8.7(0.36)\end{array}$ & $>0 \cdot 1$ \\
\hline
\end{tabular}

All measurements mean $(\mathrm{SE}) ; \mathrm{PAR}=$ pudendo-anal reflex; $\mathrm{MUPD}=$ mean motor unit potential duration.

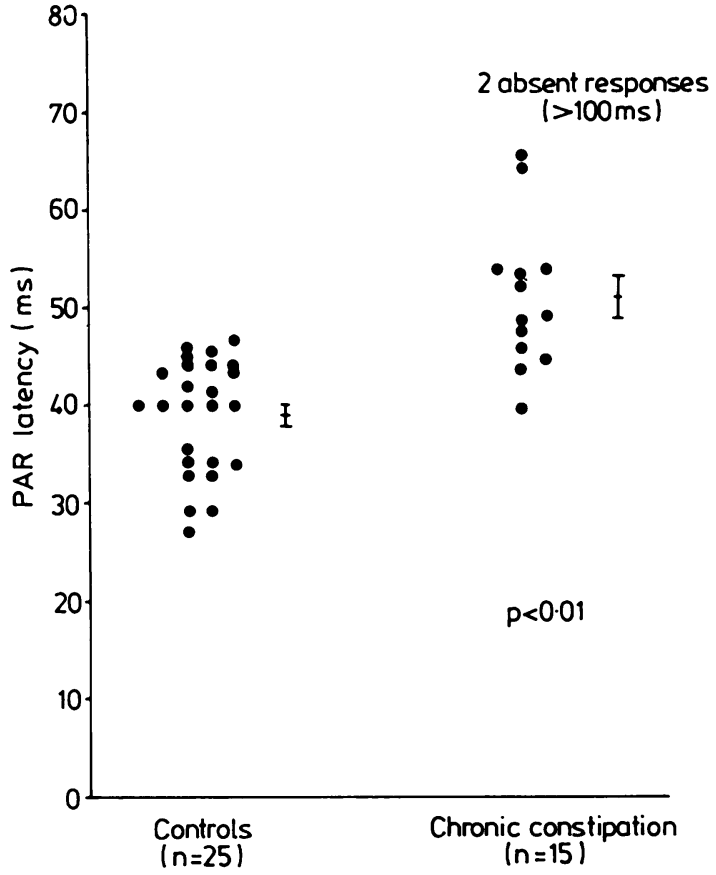

Figure Scattergram showing prolongation of latency and absence of the pudendo-anal reflex in idiopathic constipation. Bars represent mean (SE) values.

\section{ELECTROPHYSIOLOGY}

Table 2 lists the electrophysiological measurements. In two patients the pudendo-anal reflex was absent $(>100 \mathrm{~ms})$. The remainder showed significant prolongation (Figure). Other electrophysiological parameters of the pudendo-anal reflex remained unchanged. The mean motor unit potential duration of the external anal sphincter appeared to be somewhat prolonged in the constipated group although this did not reach statistical significance.

\section{Discussion}

There is no consensus regarding the pathophysiology of constipation and it has been suggested that it may be related to abnormally high sphincter pressures, ${ }^{+1522}$ an internal anal sphincter that fails to relax on rectal distension, ${ }^{13223}$ impaired rectal sensitivity, 22 failure of relaxation or paradoxical contraction of the pelvic floor musculature,,$^{5101324}$ reduced colonic propulsion,,$^{25}$ myenteric plexus abnormalities," a functional obstruction of the sigmoid colon, ${ }^{26}$ or a combination of these abnormalities. This study has examined a well defined young to middle aged group of women with severe 'idiopathic' constipation dating from adolescence. The sex and age distribution resembles that reported from other 
studies $^{1112}$ but is different from the sex distribution found in elderly patients with chronic constipation. $272 x$

Manometric anal sphincter data in this study did not throw much light on the aetiology of this type of constipation. The data are, however, in agreement with other recent reports in a similar group of patients. ${ }^{78}$ Hirschsprung's disease had been excluded by manometry and/or biopsy but not anismus which is caused by the paradoxical contraction of the pelvic floor musculature on attempted defecation. ${ }^{511}$

Although the proctometrogram in 10 patients did not show any increase in the initial sensation of rectal distension, the distending volume for the 'constant' sensation at which the urge to defecate is perceived was increased. This is in keeping with the findings of Read $e t \mathrm{al}^{7}$ who postulated different sensory pathways for these sensory modalities. The increase in rectal compliance and maximal tolerable volume in the constipated group was in contradiction to the findings of Roe et al ${ }^{*}$ who, however, used a much faster rate of infusion. An increase in rectal compliance and maximal tolerable volume in association with sensory deficits has been described in patients with spinal cord injury ${ }^{24}$ and after pelvic nerve damage. ${ }^{31131}$

Our studies suggest that some of these patients have a 'functional' megarectum that is often not obvious radiologically. ${ }^{32}$ This may be the combined effect of the outlet obstruction that has been described in many such patients ${ }^{5}$ and the coexistent sensory deficit of rectal perception of distension. A similar phenomenon has been described in some elderly patients with constipation and impaction, ${ }^{27}{ }^{28}$ although there are probably many other factors involved in that group. ${ }^{27}$

The electrophysiological results in this study do not suggest any abnormality of the sensory side of the pudendo-anal reflex as both the threshold and stimulation parameters did not significantly differ from control measurements (Table 2), although voltage is less accurate than current in quantifying this. This finding is in accordance with that of other workers ${ }^{\mathrm{x}}$ in contrast with patients with neurogenic faecal or urinary incontinence who have abnormalities of sensory and motor pathways. ${ }^{33}$

It is recognised that denervation of the striated anal sphincter musculature can result from chronic straining at defecation. ${ }^{34}$ The patients in whom mean motor unit potential duration of the external anal sphincter was assessed in this study showed a relative prolongation in this parameter although this did not achieve statistical significance compared with the control group. In contrast, the latency of the pudendo-anal reflex was grossly prolonged in constipation and was in excess of $100 \mathrm{~ms}$ in two patients.
This finding suggests a significant neurological disturbance in the central part of this reflex arc, its sensory and motor limbs being apparently intact. ${ }^{14} \mathrm{It}$ is conceivable that interneuronal connections to Onuf's nucleus ${ }^{35}$ are at fault and may be responsible for the abnormal response of the pelvic floor at defecation. Both the patients with the 'absent' reflexes had a sacral spina bifida occulta. The external sphincter mean motor unit potential duration (MUPD), however, was not greatly prolonged in these two patients. It should be noted that there is a clear relationship between the latency of the PAR and the MUPD of the external anal sphincter in neurogenic incontinence. ${ }^{19}$

The conus medullaris is intimately concerned in the modulation of colorectal motility and pelvic floor innervation ${ }^{3536}$ and in the control of micturition..$^{37.36}$ The urological disturbances noted in our patients are further pointers to a possible occult neurogenic sacral spinal cord deficit in this constipated group. These abnormalities have been noted by other workers. ${ }^{16}$ Yip et $a l^{39}$ and Jakobsen et ${ }^{40}{ }^{40}$ emphasise the importance of urodynamic evaluation in spinal dysraphism. In a large series of patients Fidas et $\mathrm{ll}^{\text {"1 }}$ reported spina bifida occulta in $50 \%$ of patients with stress urinary incontinence compared with an incidence of only $17 \%$ in asymptomatic control female subjects. In our series more than $30 \%$ of the patients had incidental lower spinal dysraphism. It is likely that the true incidence is much higher and may be an explanation for the neurophysiological abnormalities described.

An alternative explanation of the results is that there is nerve damage to the efferent side of the reflex arc. Snooks and colleagues ${ }^{42}$ have shown by transcutaneous spinal stimulation that the latency was prolonged to the puborectalis muscle in over half of a group of constipated patients and to the external anal sphincter in over one-third of the patients. Further, the latency after stimulation of the pudendal nerve before contraction of the external anal sphincter was also prolonged in 10 of 24 constipated patients. These findings did not correlate in every patient with evidence of reinnervation of the muscles as shown by single fibre electromyographic measurement of fibre density. Most (20 of 24) of their patients showed evidence of perineal descent and these workers attributed the prolonged latency to nerve damage by stretching without necessarily causing denervation of muscle. Varma, Smith, and McInnes, ${ }^{19}$ describing results in incontinent patients in a previous study, quote values for normal conduction time of approximately $8 \mathrm{~ms}$ in each of the afferent and efferent limbs of the reflex similar to that found by Snooks and colleagues $^{43}$ for conduction in the efferent limb. From this Varma et $a l^{19}$ assumed that the normal central conduction time was $15-30 \mathrm{~ms}$. They have shown in 
that study a similar prolongation of the pudendo-anal reflex in incontinent patients as occurs in the constipated patients now reported. In the previous study, the abnormal latencies in incontinent patients were attributed to a neuropathy and evidence was found for this in decreased anal resting and squeeze pressures and prolonged mean motor unit potential duration. The same inference could be made here but with less severe impairment of motor function in constipated patients possibly because of varying degrees of descent of the pelvic floor on straining. The main argument against this, however, lies in the combination of bowel and bladder problems which suggests that the function of both these organs is disturbed as a result of a more central cord disorder.

We thank Dr Angus McInnes, Department of Clinical Neurophysiology, Western General Hospital, for his technical advice on the electrophysiological measurements. JSV was supported by a Wellcome Trust Research Grant.

Paper read in part to the 45th Annual Meeting of The British Society of Gastroenterology, Liverpool, 14th September 1984.

\section{References}

1 Moore-Gillon V. Constipation: what does the patient mean? J R Soc Med 1985; 77: 108-10.

2 Lennard-Jones JE. Constipation: pathophysiology, clinical features and treatment. In: Henry MM, Swash $\mathrm{M}$, eds. Coloproctology and the pelvic floor. London: Butterworths, 1985.

3 Preston DM, Lennard-Jones JE. Severe chronic constipation of young women: 'Idiopathic slow-transit constipation'. Gut 1986; 27: 41-8.

4 Watier A, Devroede G, Duguay C, Duranceau A, Arhan P, Toppercer A. Mechanisms of idiopathic constipation: colonic inertia [Abstract]. Gastroenterology 1979; 76: 1267.

5 Preston DM, Lennard-Jones JE. Anismus in chronic constipation. Dig Dis Sci 1985; 30: 413-8.

6 Krishnamurthy S, Schuffler MD, Rohrmann CA, Pope CA. Severe idiopathic constipation is associated with a distinctive abnormality of the colonic myenteric plexus. Gastroenterology 1985; 88: 26-34.

7 Read NW, Timms JM, Barfield LJ, Donnelly TC, Bannister JJ. Impairment of defaecation in young women with severe constipation. Gastroenterology 1986; 90: 53-60.

8 Roe AM, Bartolo DCC, Mortensen NJMcC. Diagnosis and surgical management of intractable constipation. $\mathrm{Br}$ J Surg 1986; 73: 854-61.

9 Barnes PRH, Hawley PR, Preston DM, Lennard-Jones J. Experience of posterior division of the puborectalis muscle in the management of chronic constipation. $\mathrm{BrJ}$ Surg 1985; 72: 475-7.

10 Barnes PRH, Lennard-Jones JE. Patients with constipation of different types have difficulty in expelling a balloon from the rectum. Gut 1984; 24: 562-3.
11 Womack NR, Williams NS, Holmfield JHM, Morrison JFB, Simpkin KC. New method for the dynamic assessment of anorectal function in constipation. Br J Surg 1985; 72: 994-8.

12 Kuipers HC, Strijk SP. Diagnosis of disturbances of continence and defaccation. Dis Colon Rectum 1984; 27: 658-62.

13 Martelli H, Devroede G, Arhan A, Duguay C. Mechanisms of idiopathic constipation: outlet obstruction. Gastroenterology 1978; 75: 623-31.

14 Abdel-Rahman M. Toppercer A, Duguay C, et al. Urorectodynamics in patients with colonic inertia. Urology 1981; 18: 428-32.

15 Watier A, Devroede G, Duranceau A, et al. Constipation with colonic inertia. A manifestation of systemic disease? Dig Dis Sci 1983; 28: 1025-33.

16 Bannister JJ, Lawrence WT, Smith A, Thomas DG, Read NW. Urological abnormalities in young women with severe constipation. Gut 1988; 29: 17-20.

17 Varma JS, Smith AN. Anorectal profilometry with the microtransducer. Br J Surg 1984; 71: 867-9.

18 Varma JS, Smith AN. Reproducibility of the proctometrogram. Gut 1986; 27: 288-92.

19 Varma JS, Smith AN, McInnes A. Electrophysiological observations on the human pudendo-anal reflex. $J$ Neurol Neurosurg Psychiatry 1986; 49: 1411-6.

20 Bartolo DCC, Jarratt JA, Read NW. The use of conventional electromyography to assess external sphinter neuropathy in man. $J$ Neurol Neurosurg Psychiatry 1983; 46: 1115-8.

21 Buchtal F. Pinelli P. Action potentials in muscular atrophy of neurogenic origin. Neurology 1953; 3: 591-603.

22 Meunier P, Marechal JM, de Beaujeu MJ. Rectoanal pressures and rectal sensitivity studies in chronic childhood constipation. Gastroenterology 1979; 77: 330-6.

23 Orr WC, Robinson MG. Motor activity of the rectosigmoid in patients with chronic constipation [Abstract]. Gastroenterology 1981; 80: 1244.

25 Preston DM, Lennard-Jones JE. Is there a pelvic floor disorder in slow-transit constipation? Gut 1981; 22: 890.

25 Ritchie JA. Colonic motor activity and bowel function. Part II. Distribution and incidence of motor activity at rest and after food and carbachol. Gut 1968; 9: 502-11.

26 Chowdhury AR, Dinoso VP, Lorber SH. Characterisation of a hyperactive segment at the rectosigmoid junction. Gastroenterology 1976; 71: 584-8.

27 Varma JS, Bradnock J, Smith RG, Smith AN. Constipation in the elderly - a physiological study. Dis Colon Rectum 1988; 31: 111-5.

28 Read NW, Abouzekry L, Read MG, et al. Anorectal function in elderly patients with faecal impaction. Gastroenterology 1985; 89: 959-66.

29 White JC, Verlot MG, Ehrentheil O. Neurogenic disturbances of the colon and their investigation by the colon metrogram. Am Surg 1940; 112: 1042-7.

30 Scott WH, Cantrell JR. Colon metrographic studies of the effects of section of the parasympathetic nerves of the colon. Bull John Hopkins Hosp 1969; 85: 310-9.

31 Varma JS, Smith AN. Abnormalities of colorectal function in intractable constipation following hysterectomy. Gut 1985; 26: 581-2. 
32 Preston DM, Lennard-Jones JE, Thomas BE. Towards a radiological diagnosis of idiopathic megacolon. Gastro-intest Radiol 1985; 10: 167-9.

33 Varma JS, Fidas A, Longmore J, McInnes A, Smith AN, Chisholm GD. Neurophysiological abnormalities in female stress urinary incontinence. $\mathrm{Br} J$ Obstet Gynaec 1988 (In press).

34 Kiff ES, Barnes PRH, Swash M. Evidence of pudendal neuropathy in patients with perineal descent and chronic straining at stool. Gut 1984; 11: 1279-84.

35 Onuf B. On the arrangement and function of the cell groups of the sacral region of the spinal cord in man. Arch Neurol Psych Pathol 1901; 3: 388-412.

36 Varma JS, Binnie N, Smith AN, Creasey GH, Edmond $P$. Differential effects of sacral anterior root stimulation on anal sphincter and colorectal motility in spinally injured man. Br J Surg 1986; 73: 478-82.

37 Denny-Brown D, Robertson EG. On the physiology of micturition. Brain 1933; 56: 149-90.

38 Mahony DT, Laferte RD, Blais DJ. Integral storage and voiding reflexes. Urology 1977; 9: 95-106.

39 Yip CM, Leah GE, Rosenfeld DS, Zimmern P, Raz S. Delayed diagnosis of voiding dysfunction: occult spinal dysraphism. J Urol 1985; 134: 694-7.

40) Jakobsen H, Holm-Bentzen M, Hald T. Neurologic bladder dysfunction in sacral agenesis and dysgenesis. Neurol Urodyn 1985; 4: 99-105.

41 Fidas A, MacDonald HL, Elton RA, McInnes A, Brown A, Chisholm GD. Neurophysiological measurements in patients with stress incontinence of urine and the relation of neurogenic defects to the presence of spina bifida occulta. BrJ Urol 1988 (In press).

42 Snooks SJ, Barnes PRH, Swash M, Henry MM. Damage to the innervation of the pelvic floor musculature in chronic constipation. Gastroenterology 1985; 89: 977-81. 